\section{Commentary: Bringing life to the golden years}

\author{
Joseph S. Coselli, MD
}

The effects of population aging are acutely felt in Japan. Life expectancy increased substantially among the Japanese population from 1960 to $2018,{ }^{1}$ and this trend is projected to continue into the 2060s. Consequently, because of agerelated atherosclerotic degeneration, increasing numbers of patients are presenting with aortic disease. ${ }^{2}$ Although the outcomes of open aortic arch repair have improved drastically during the past decade, total aortic arch replacement remains controversial in octogenarian patients. Because endovascular repair of the aortic arch is largely experimental and often requires weeks of operative planning, few options exist for octogenarians presenting for repair in an acute, life-threatening condition; however, we know that complex aortic repair is inherently risky in elderly patients. ${ }^{3}$ The question we must ask is whether total aortic arch replacement should be considered in patients 80 years of age and older.

In this issue of the Journal, Ikeno and colleagues ${ }^{4}$ evaluate the outcomes of total transverse aortic arch replacement as performed in 740 Japanese patients during an 18 -year period. In all patients, antegrade selective cerebral perfusion for brain protection was provided under moderate hypothermic conditions. The elephant trunk procedure was typically used in patients with DeBakey type I acute aortic dissection, as well as those patients with a dilated descending thoracic or thoracoabdominal aorta. Nearly $20 \%$ of patients were 80 years of age or older $(n=139)$. Four patients were nonagenarians. Rupture was more than 3 times more common in octogenarians than in patients younger than

\footnotetext{
From the Division of Cardiothoracic Surgery, Michael E. DeBakey Department of Surgery, Baylor College of Medicine, Houston, Tex; Department of Cardiovascular Surgery, Texas Heart Institute, Houston, Tex; and Department of Cardiovascular Surgery, CHI St Luke's Health-Baylor St Luke's Medical Center, Houston, Tex.

This editorial was not funded. Dr Coselli's work is partly supported by the Cullen Foundation.

Disclosures: Dr Coselli participates in clinical trials with or consults for Terumo Aortic, Medtronic, W. L. Gore, Edwards Lifesciences, and Abbott Laboratories, and he receives royalties and grant support from Terumo Aortic.

Received for publication July 26, 2019; accepted for publication July 29, 2019; available ahead of print Sept 5, 2019.

Address for reprints: Joseph S. Coselli, MD, One Baylor Plaza, BCM 390, Houston, TX 77030 (E-mail: jcoselli@bcm.edu).

J Thorac Cardiovasc Surg 2020;160:357-8

0022-5223/\$36.00

Copyright (c) 2019 by The American Association for Thoracic Surgery

https://doi.org/10.1016/j.jtcvs.2019.07.120
}

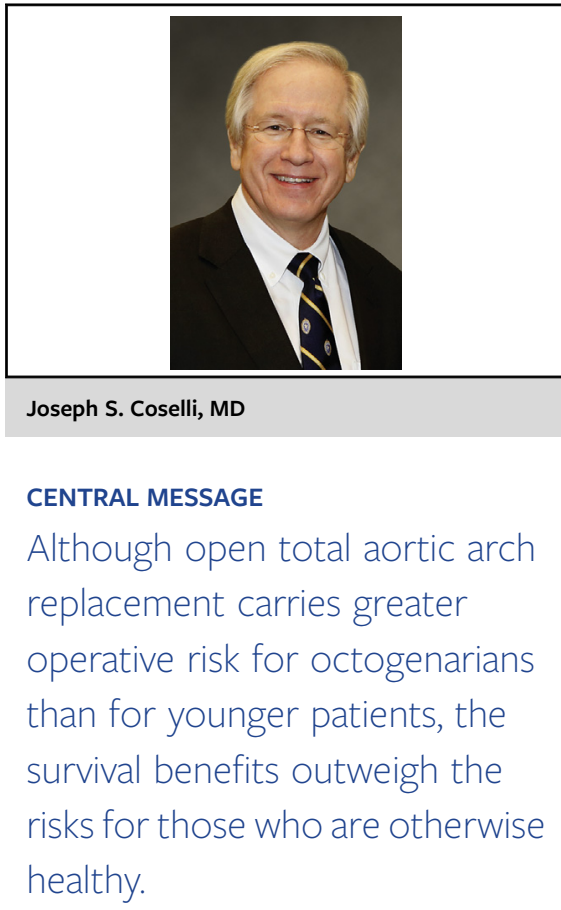

80 years old ( $13 \%$ vs $4 \%$, respectively). In addition, approximately $10 \%$ of the octogenarian patients presented with acute dissection $(\mathrm{n}=15)$. Urgent and emergency cases accounted for $7 \%(n=10)$ and $20 \%(n=28)$ of procedures, respectively. In more than $20 \%$ of octogenarians, aortic arch repair was extended into the distal aorta by using an elephant trunk approach $(n=27)$ or a frozen elephant trunk approach $(\mathrm{n}=4)$, and $28 \%$ underwent concomitant coronary artery bypass grafting.

Compared with younger patients, older patients had a greater incidence of certain postoperative complications, chiefly deep sternal wound infection, pneumonia, and respiratory complications necessitating tracheostomy. In addition, the operative mortality rate in the octogenarian patients was $9 \%(\mathrm{n}=12)$, which was significantly higher than the rate in the patients younger than 80 years $(4 \%)$ but still well within the range of reasonable outcomes. Significant risk factors for mortality in the octogenarian cohort included chronic kidney disease, nonelective surgery, and concurrent procedures. Notably, Ikeno and colleagues ${ }^{4}$ performed a large number of stage 1 elephant trunk repairs. These repairs are technically more complex to perform than a standard total arch replacement repair. The value of performing such repair in patients with presumably limited life spans is questionable, especially in patients with acute DeBakey type I aortic dissection; it remains unclear how many such patients underwent stage 2 completion procedures. 
Although open surgical replacement of the transverse aortic arch carries greater operative risk for octogenarians than for younger patients, without repair these patients would probably not survive beyond a few years' time, and perhaps much less. Ikeno and colleagues ${ }^{4}$ are to be commended for their excellent results in a set of elderly patients with complex aortic disease; however, further study is critical to evaluating the value of these complex aortic repairs in elderly patients. Most octogenarians accept that repair risks death, but they fear survival with a catastrophic neurologic event.

\section{References}

1. Statistics Japan. 2015 national census. Available at: http://www.stat.go.jp/data/ kokusei/2015/index.html. Accessed July 17, 2019.

2. Shijo T, Kuratani T, Torikai K, Shimamura K, Sakamoto T, Kudo T, et al. Thoracic endovascular aortic repair for degenerative distal arch aneurysm can be used as a standard procedure in high-risk patients. Eur J Cardiothorac Surg. 2016;50: 257-63.

3. Aftab M, Songdechakraiwut T, Green SY, Zarda S, Price MD, Nalty CC, et al. Contemporary outcomes of open thoracoabdominal aortic aneurysm repair in octogenarians. J Thorac Cardiovasc Surg. 2015;149(2 Suppl):S134-41.

4. Ikeno Y, Yokawa K, Yamanaka K, Inoue T, Tanaka H, Okada K, et al. Total arch replacement in octogenarians and nonagenarians: a single-center 18-year experience. J Thorac Cardiovasc Surg. 2020;160:346-56.e1.
See Article page 346.

\section{Commentary: Still not too old for surgery!}

\author{
Sung Jun Park, MD, and Joon Bum Kim, MD, PhD
}

The pace of population aging is faster than ever, and it is expected to accelerate even more for a while. Led by highincome countries like Japan, the World Health Organization projects that the world's population aged 80 years or older will be 434 million worldwide by 2050 , up from 125 million in $2015 .{ }^{1}$ South Korea is not an exception; it is also rapidly catching up this trend and is projected to be the country of longest life expectancy by $2030 .^{2} \mathrm{We}$, as citizens of the nearest neighboring country to Japan, thus have very special interests on the article by Ikeno and colleagues ${ }^{3}$ in the current issue of the Journal. Through this article, Ikeno and colleagues $^{3}$ sought to give insights into a feasibility issue of high-risk extensive arch surgeries in very elderly patients in a timely manner. In this single-center observational study from Japan, they evaluated 139 patients aged 80 years or older who underwent total arch replacement. Despite a higher risk of operative mortality $(8.6 \%$ vs $4.0 \%$; $P=.01)$ in this aged group relative to younger individuals

From the Department of Thoracic and Cardiovascular Surgery, Asan Medical Center, University of Ulsan College of Medicine, Seoul, Republic of Korea.

Disclosures: Authors have nothing to disclose with regard to commercial support.

Received for publication Sept 26, 2019; revisions received Sept 26, 2019; accepted for publication Sept 26, 2019; available ahead of print Oct 9, 2019.

Address for reprints: Joon Bum Kim, MD, PhD, Department of Thoracic and Cardiovascular Surgery, Asan Medical Center, University of Ulsan College of Medicine, 88 Olympic-Ro-43-Gil, Songpa-Gu, Seoul, Republic of Korea 05505 (E-mail: jbkim1975@amc.seoul.kr).

J Thorac Cardiovasc Surg 2020;160:358-9

$0022-5223 / \$ 36.00$

Copyright (c) 2019 by The American Association for Thoracic Surgery

https://doi.org/10.1016/j.jtcvs.2019.09.131
Check for updates

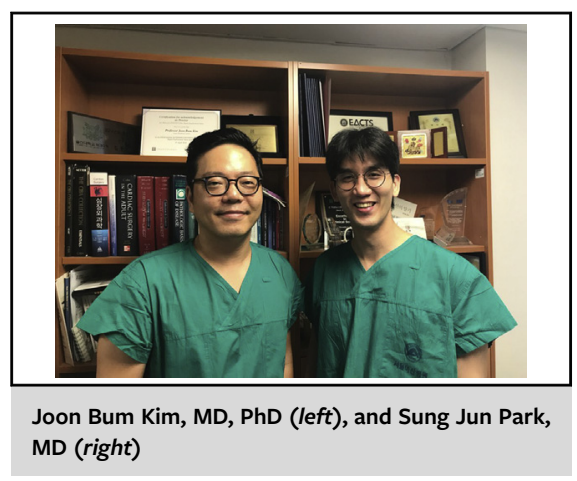

CENTRAL MESSAGE

On the horizon of "super-aged society," discussions regarding cardiovascular research are moving forward, reproducing benefits of such complex procedures as total arch repair in very elderly patients.

( $n=601)$, it will probably be regarded as an excellent result for this extensive procedure, and interestingly, the rate of permanent neurologic deficit was as low as that of the younger group $(4.3 \%$ vs $3.7 \% ; P=.72)$. When compared with an age- and sex-matched Japanese general population, survival outcomes of these elderly patients ( $\geq 80$ years) undergoing total arch repair were significantly poorer; however, the landmark analysis revealed that the high mortality risk was confined within 1 postoperative year. Indeed, the survival outcomes after 1 year of surgery were comparable to matched general population. 